\title{
UM ESTUDO LOCAL SOBRE A FORMAÇÃO DE PROFESSORES EM BIRIGUI/SP: VOCAÇÃO/MOTIVAÇÃO E FORMAÇÃ̃O
}

\author{
A local study on teacher training in Birigui /SP: vocation / motivation and training
}

\author{
Un estudio local sobre la formación de profesores en Birigui/SP: vocación / \\ motivación y formación
}

$\begin{array}{r}\text { Áurea Esteves Serra } \\ \text { Luzia de Fátima Paula** } \\ \hline\end{array}$

Resumo

Este texto tem por objetivo contribuir à compreensão da escolha da carreira docente e formação de professoras aposentadas da rede de ensino pública do estado de São Paulo, nas escolas rurais e urbanas da região de Birigui/SP. Delimita-se 1944, ano de ingresso no curso normal da professora mais velha do grupo, a 1991, ano de aposentadoria da professora mais jovem. A análise ocorreu a partir de bibliografia especializada sobre o tema e corpus das entrevistas transcritas das quatro professoras que relataram a memória vivida. Trata-se de um estudo local, mas com possibilidades de compreensão dos cursos de formação de professores do estado de São Paulo e dos aspectos que contribuíam para que uma jovem se motivasse à escolha da carreira docente. Os resultados obtidos apontam para o fato de que dentre as professoras, três participaram da formação inicial em escolas primárias rurais; a partir do ginásio, todas estudaram em escolas urbanas e prosseguiram nos estudos até a finalização do curso normal. Uma delas apenas cursou a Pedagogia. Quanto à vocação/motivação, as narrativas permitem compreender que as experiências vivenciadas durante a vida escolar pelas professoras contribuíram para a formação de cada uma delas, que participaram da história da formação de professores do município de Birigui/SP.

PALAVRAS-CHAVE: Formação de professores. Vocação/Motivação. Magistério.

\begin{abstract}
This text aims to contribute to the understanding of the choice of teaching career and training of retired teachers from the public education network of the state of São Paulo, in rural and urban schools in the region of Birigui / SP. 1944, the year of entry into the normal course of the oldest teacher in the group, is delimited to 1991, the year of retirement of the youngest teacher. The analysis occurred from a specialized bibliography on the theme and corpus of the transcribed

\footnotetext{
* Graduada em Pedagogia e História, com especialização em Liderança e Gestão Pública, Direito Educacional e Gestão Escolar. Mestre e Doutora em Educação pela UNESP (Campus de Marília). Pósdoutorado em Educação Escolar pela UNESP (Campus de Araraquara). E-mail: aureaserra1963@gmail.com.

** Graduada em Pedagogia e Letras; Mestre e Doutora em Educação pela UNESP (Campus de Marília). professora e coordenadora de curso na Faculdade de Mirassol - FAIMI. Endereço: R. Sétima Dahma, n. 143, Mirassol/SP, 17 991074608. Email: luzfapa@gmail.com.
} 
interviews of the four teachers who reported the lived memory. This is a local study, but with possibilities for understanding teacher training courses in the state of São Paulo and the aspects that contributed to motivating a young woman to choose a teaching career. The results obtained point to the fact that among the teachers, three participated in the initial training in rural primary schools; from the gymnasium, they all studied in urban schools and continued their studies until the end of the normal course. One of them just studied Pedagogy. As for the vocation / motivation, the narratives allow us to understand that the experiences lived during school life by teachers contributed to the formation of each one of them, who participated in the history of teacher education in the municipality of Birigui/SP.

KEYWORDS: Teacher training. Vocation / Motivation. Magisterium.

\section{Resumen}

Este texto tiene como objetivo contribuir a la comprensión de la elección de la carrera docente y la capacitación de maestros jubilados de la red de educación pública del estado de São Paulo, en escuelas rurales y urbanas de la región de Birigui / SP. 1944, el año de entrada en el curso normal del maestro más viejo del grupo, se delimita a 1991, el año de jubilación del maestro más joven. El análisis se produjo a partir de una bibliografía especializada sobre el tema y el corpus de las entrevistas transcritas de los cuatro maestros que informaron sobre la memoria vivida. Este es un estudio local, pero con posibilidades de comprender los cursos de formación de docentes en el estado de São Paulo y los aspectos que contribuyeron a motivar a una joven a elegir una carrera docente. Los resultados obtenidos apuntan al hecho de que entre los docentes, tres participaron en la capacitación inicial en escuelas primarias rurales; Desde el gimnasio, todos estudiaron en escuelas urbanas y continuaron sus estudios hasta el final del curso normal. Uno de ellos acaba de estudiar Pedagogía. En cuanto a la vocación / motivación, las narraciones nos permiten comprender que las experiencias vividas durante la vida escolar por parte de los docentes contribuyeron a la formación de cada uno de ellos, quienes participaron en la historia de la formación docente en el municipio de Birigui/SP.

PALABRAS CLAVE: Formación docente. Vocación / Motivación. Magisterio.

\section{INTRODUÇÃO}

A formação de professores é tema permanente de reflexões e estudos, entre docentes e pesquisadores, dada a sua natureza complexa, tendo em vista os diferentes movimentos, situações, espaços e tempos. Entendendo que esse processo é parte de uma dinâmica de desenvolvimento pessoal, busca-se compreender a formação como uma construção pessoal no contexto social em que está inserida.

Assim, neste texto, propõe-se uma análise da formação inicial, da vocação/motivação para o magistério e da respectiva formação das professoras, utilizando fontes orais como opção teórico-metodológica em pesquisas educacionais. Para isso, foram entrevistadas quatro professoras, todas aposentadas, ex-integrantes da rede de ensino pública do estado de São Paulo, que atuaram entre os anos de 1946 e 1991, nas escolas rurais pertencentes à Delegacia de Ensino ${ }^{1}$ da região de Birigui.

\footnotetext{
${ }^{1}$ De acordo com Serra (2014), o ensino na região de Birigui esteve por um longo período vinculado à Delegacia de Ensino da cidade de Lins, depois à Delegacia de Ensino de Araçatuba, criada no ano de 1947, por meio do Decreto no ${ }^{\circ}$ 17.698, de 26 de novembro de 1947. E somente em 1976, com o Decreto
}

Educação e Fronteiras On-Line, Dourados/MS, v.9, n.26 p.60-71, maio/ago. 2019 
Para Alberti (1996, p.12), "[...] o destaque para ação de constituição de memórias, não é o processo cognitivo de rememoração e esquecimento, e sim a transformação daquela ação em objeto de estudo". Neste sentido, a investigação teve por objetivo analisar as trajetórias de formação mediante as narrativas, para compreender como ocorreu a construção para essas professoras das disposições para a formação e consequente atuação docente.

Sobre o conceito de narrativa, tal como apresenta Bosi (2003), trata-se de uma melodia do passado interpretada no presente, porque, ao narrar, os entrevistados criam uma nova ordem, isto é, uma cronologia própria, ancorada nos marcos sociais e nas referências que os formaram e marcaram.

Com isso, o estudo privilegiou a construção das narrativas, partindo do pressuposto de que as experiências escolares vivenciadas contribuem de forma significativa para a profissão docente.

Sobre a questão abordada neste texto relativa à formação de professores para o magistério, compreende-se, de acordo com Tardif (2002) que: o saber docente é composto de fontes disciplinares, curriculares, profissionais e experienciais; destacando os saberes experienciais como os fundamentos da prática e da competência profissional. Ele também afirma que: "Os saberes práticos brotam da experiência e são por ela validados, e incorporam-se à experiência individual e coletiva sob a forma de habitus e habilidades, de saber-fazer e de saber-ser". (TARDIF, 2002, p. 33) contribui:

E ainda, com relação ao conceito de vocação/motivação, Lengert (2011) assim

\begin{abstract}
A "vocação", portanto, não é subjetiva, mas depende da construção de um imaginário pessoal e principalmente social sobre a profissão docente. A escolha por ser professor é uma construção e não pode ser encarada apenas como uma vocação individual numa progressão linear e sucessiva. (p. 19)
\end{abstract}

Dessa forma, pretende-se compreender como a construção da formação do professor parte da vocação/motivação para o exercício propriamente dito do magistério, unindo as experiências de cada professora, formando-as na prática da sala de aula, mas também na própria narrativa quando a elas se referem, já que quando refletem sobre a prática tornam evidente como foram vivenciando a própria formação.

\title{
O ENSINO NORMAL EM BIRIGUI
}

O ensino normal no Brasil foi oficializado com a Lei Orgânica do Ensino Normal, mediante o Decreto-lei n.8530, de 2 de janeiro de 1946, que compreendia cursos de $1^{\circ}$ e $2^{\circ}$ ciclos, em estabelecimentos denominados Escolas Normais.

De acordo com Serra (2007), no município de Birigui, existiram três escolas normais, sendo duas Escolas Normais Livres e uma Escola Normal Oficial. A seguir, de posse dos estudos realizados por Serra (2007), passa-se a discorrer sobre essas três instituições de formação de professores, instituições essas onde as quatro professoras fizeram o curso normal.

7510, de 29/01/1976, foi criada a Delegacia de Ensino de Birigui, existente até hoje, 2020, com o nome de Diretoria de Ensino. 
O ensino normal teve início na cidade de Birigui na década de 1940 e foi oferecido em três escolas da cidade: no colégio Metodista "Instituto Noroeste de Birigui", onde foi criada a Escola Normal Livre², em 1944; no Externato Católico "Sagrado Coração de Maria", criado em 1957; e no Colégio e Escola Normal Estadual "Prof. Stélio Machado Loureiro", criado em 1958.

Em 1944, no Colégio Metodista "Instituto Noroeste de Birigui", começou a ser formada a primeira turma da Escola Normal Livre de Birigui. Nessa escola funcionou, de fato, o curso Pré-Normal, de 1944 a 1947, que, a partir de 1947, passou a se denominar Curso Normal, assim permanecendo até 1974. Nessa ocasião, as escolas normais estavam se adaptando à Lei $\mathrm{n}^{\circ}$ 5692/71, que modificou a denominação do Curso Normal para Habilitação Específica para o Magistério (HEM). Essa habilitação permaneceu em funcionamento até o ano de 2000, quando foi definitivamente extinta, em decorrência da Lei de Diretrizes e Bases da Educação Nacional (Lei n. 9394/96).

No ano de 1956, precisamente em 16/06/1956, foi criado o Curso Normal no Externato Católico "Sagrado Coração de Maria", hoje Colégio "Sagrado Coração de Jesus", curso mantido pela Associação das Irmãs Missionárias Zeladoras do Sagrado Coração de Jesus, que começou a funcionar em 11/03/1957, após autorização por meio do Decreto 26.120, de 16/07/1956, e reconhecimento por meio do Decreto 38.226, de 21/03/1961. Com a criação desse curso normal, o externato passou a se denominar também de Escola Normal "Sagrado Coração de Maria". Esse Curso Normal somente tinha turmas mistas e funcionou inicialmente com a $1^{\mathrm{a}}$ série diurna e $2^{\mathrm{a}}, 3^{\mathrm{a}}$ e $4^{\mathrm{a}}$ séries noturnas, organizado de acordo com o Ensino Normal do $2^{\circ}$ Tipo, conforme estabelecido no Decreto n. 5.844 de 21/4/1933. De acordo com o artigo 784 do Decreto citado acima, "[...] o ensino normal feito no Curso de Formação do Professor compreende dois anos de estudo".

A Escola Normal, de confissão católica, ofereceu o curso normal em quatro anos, mas o curso complementar ao ginásio, cursado antes do normal, tinha duração de dois anos. Esse curso, acontecia a partir da $3^{\text {a }}$ série primária e isso aconteceu nessa época, por incentivo do governo estadual, para a realização de cursos rápidos e intensivos que agilizavam a escolarização da população. Essa Escola Normal também mantinha um curso primário, o qual servia como "escola de aplicação", destinada às aulas práticas e ao estágio.

Em 1974, foi criada, nessa escola, a HEM, mediante a Portaria da Coordenadoria do Ensino Básico e Normal (CEBN), 04/01/1973, e o Curso Normal foi extinto no Colégio "Sagrado Coração de Jesus”, em 1977.

Mediante o Decreto-lei n. 16.960, foi criado, no dia 22/2/1947, o Ginásio Estadual de Birigui, instalado em 15/3/1948. Já a escola normal oficial demorou a chegar à cidade e sua criação só acontece em 1958, cuja instalação se deu em $1^{\circ}$ de março de 1960, mudando-se, então, a denominação de Ginásio Estadual "Prof. Stélio Machado Loureiro" para Colégio Estadual e Escola Normal "Prof. Stélio Machado Loureiro". Em março de 1960, teve início nessa escola o curso Formação de professores primários, e só em 1963, o curso normal, em funcionamento até 1975.

\footnotetext{
${ }^{2}$ Escola Normal Livre era uma escola mantida por iniciativa privada para formar professores. A esse respeito, ver, especialmente, Tanuri (1979).
} 
O currículo do curso normal do IEE "Prof. Stélio Machado Loureiro" era constituído de disciplinas que se distribuíam de acordo com as séries:

$-1^{a}$ série: Português e Literatura Infantil, Matemática e Estatística, Ciências, História da Civilização Brasileira, Geografia, Metodologia e Prática, Pedagogia e Psicologia e Desenho Pedagógico.

-2a série: Português, Metodologia e Prática, Psicologia da Educação, Sociologia Educacional, Biologia Educacional e Desenho Pedagógico.

$-3^{\mathrm{a}}$ série: Português, Metodologia e Prática, Psicologia da Educação, Filosofia e História da Educação e Desenho Pedagógico.

O Curso Normal do IEE "Prof. Stélio Machado Loureiro" se incluía nas Escolas Normais de $2^{\circ}$ ciclo.

A partir de 1976, a denominação do Curso Normal passa a ser HEM, de acordo com a lei 5.692/71. E com o Decreto 7.510, de 26 de janeiro de 1976, publicado no Diário Oficial do Estado de São Paulo, o IEE "Prof. Stélio Machado Loureiro" passou a ser denominado de EEPSGs "Prof. Stélio Machado Loureiro". A HEM continua funcionando até o ano de 1998, quando foi extinta. Com o parecer 67/98, aprovado em 18/03/98 e publicado em 21/03/98, que estabelece Normas Regimentais Básicas para as Escolas Estaduais do Estado de São Paulo, que ministram o ensino fundamental, médio, educação de jovens e adultos e educação profissional, a escola passou a se denominar Escola Estadual "Prof. Stélio Machado Loureiro", assim permanecendo até os dias de hoje.

Vale ressaltar que a Escola Normal do IEE "Prof. Stélio Machado Loureiro" assumiu o topo da hierarquia das instituições formadoras de professores da cidade de Birigui, entre as quais figuravam o Colégio Metodista "Instituto Noroeste de Birigui" e o Colégio Católico Externato "Sagrado Coração de Maria".

O Curso Normal do Instituto Estadual "Prof. Stélio Machado Loureiro" ganhou status e prestígio em toda a região, ficando dessa maneira explícito o fenômeno de surgimento e consolidação das escolas normais em Birigui/SP, assim como aconteceu em todo Brasil, de acordo com Saviani (2008).

\section{FORMAÇÃO INICIAL, VOCAÇÃO/MOTIVAÇÃO E MAGISTÉRIO}

A partir das narrativas orais com as quatro professoras já apresentadas, buscouse compreender como ocorreu a formação inicial delas, na infância e na adolescência. E sobre essa questão, elas comentam que:

Ah minha filha, é um tempo que sinto muitas saudades, eu fui criada no sítio,
meu pai tinha sítio, até 15 anos eu morei no sítio, o sítio da Família Fonzar.
Lá tinha uma escolinha que eu comecei a estudar, foi lá no sítio mesmo,
bairro da Estiva, e lá tinha uma escolinha que era no nosso sítio, onde eu
morava, e a professora ficou os três anos. Eu entrei com seis, sete, oito, na
quarta série ela veio para a cidade e trouxe a turma toda para cá, é que não
comportava o estudo lá. A gente fez a quarta série aqui nesse grupo, nesse
grupo grande da praça, acho que é Roberto Clark. Eu ficava na casa da minha
avó e no fim de semana eu ia para o sítio. Mas aos 15 anos quando os outros
irmãos começaram a vir para cá, meu pai mudou para cá. Eu fiquei interna no
colégio de Cafelândia um ano só, porque meu pai pretendia pôr a gente lá, 
mas depois resolveu mudar para cidade e todo mundo ficou em casa. (MESQUITA, 2018).

\section{Como menciona Bilia (2018), as histórias iniciais são longas e cheias de aspectos que contribuem para essa futura formação/vocação no magistério:}

É longa minha história. Então, aos três aninhos de idade, eu morava num sítio no bairro que se chamava Córrego da Pedra e morava com meus pais naturalmente, e eu era a última filha, a caçulinha. Naquele tempo alguns comerciantes com poderio mais fraco, iam até a roça para comprar ovos, frangos, o que tinha de mais fartura nas casas dos sítios, eles compravam. E eu, quando chegava em nossa casa esse comprador que ia comprar ovos e frango lá, eu ficava perto dele e enquanto ele estava negociando, eu tinha três aninhos de idade. Dizem que eu era muito conversadeira, então eu ficava perguntando uma coisa, perguntando outra coisa e ele respondia. A mulher dele não tinha filho nenhum, e quando ele chegava em sua casa, comentava com a esposa "olha lá na casa dos Bertechini tem uma garotinha que é uma coisa, ela quer saber tudo, fica conversando o tempo todo que a gente está contando os ovos" e a esposa dele dizia: "traz ela para passar uns dias aqui com a gente", mas ele dizia: imagina que a família iria deixar. Mas ele tentou pedir e meus pais deixaram. E com isso minha filha eu fui criada aqui na cidade, eu voltava lá pro sítio muito pouco. Eu tenho impressão que meus pais deixaram, porque antigamente a casa que nós morávamos lá, eram três famílias, minha mãe era mãe de oito, então eu acho que um a menos pra ela foi um alivio, ainda mais que eu era conversadeira. Então eu ia lá visitava, mas na mesma hora dizia que queria voltar e assim foi. E essa mulher era professora leiga aqui em Birigui ela lecionava na casa dela e eu comecei a frequentar a escolinha dela também junto com a molecada. E eu sei que muito cedo eu aprendi a ler e escrever, muito cedo, com 5 aninhos eu já lia e escrevia, porque eu não saia de perto dela, e eu era a única pessoa que eles tinham.

Eu gostava muito do tratamento, porque onde eu morava tinha um monte de criança e eu às vezes até desaparecia, e fui para um lugar onde era só eu. Eu não era crismada, então minha mãe falava: "Meu Deus, mas essa menina está ficando lá e como é que ela chama vocês?" E ele respondeu que eu os chamava pelo nome. Então ela decidiu que eles seriam meus padrinhos de crisma, e eu deveria os chamar de padrinho e madrinha, porque pai e mãe eu já tinha né. Então a partir daquele momento a minha mãe falou pra mim que eu deveria sempre chamar o Sr. Liberal de padrinho e a Dona Bella de madrinha, e eu nunca mais os tratei de outro jeito.

E daí chegou meu período escolar, e assim acabou essa história de voltar para o sitio, apesar de que eu ia de vez em quando, depois eu comecei a ir somente nos tempos de férias, porque com cinco, seis aninhos eu já comecei a fazer o jardim. Nas férias eu ia e ficava só dois, três dias e queria voltar, porque não tinha comparação o ambiente de lá com o daqui né, e eu preferia ficar aqui. E foi assim que eu fiz a pré-escola e acho que foi até com a madrinha mesmo, porque ela dava pré-escola e reforço. Então eu entrei no Grupo Escolar Roberto Clark e fiz o primário lá. (BILIA, 2018)

As necessidades também "formam", e à medida que se lançam em suas atividades de formação inicial, as professoras vão se construindo, assim como afirma Marcório (2018):

O pai veio a falecer e a mãe estava grávida de 4 meses de mim (Maria Ceris), tinha a irmã mais velha ( 3 anos). Passou 7 anos a mãe se casou novamente, teve 2 filhos, Marisa e José Carlos, vida normal tranquila, pois não se tinha opções de brinquedo, era aqueles brinquedo corriqueiro, fazia peteca com palha de milho, jogo de bola, bilboquê... Ah! minha infância foi gostosa, 
naquela época não tinha asfalto, nós brincávamos de pique, queimada, tudo na rua. (MARCÓRIO, 2018).

\section{De acordo com Matos, Serra e Thomazin (2017),}

A professora Maria Céris deu início aos seus estudos cursando o primeiro ano do chamado Curso Primário no antigo Primeiro Grupo Escolar da cidade de Birigui, hoje denominado de Escola Municipal "Roberto Clark". Após concluir o Ensino Primário foi transferida para o Colégio Metodista "Instituto Noroeste", onde realizou o $5^{\circ}$ ano do Curso Ginasial. Maria Céris mudou-se de casa com sua família e o Colégio Instituto Noroeste era longe da sua nova casa, seus pais a transferiram para o Instituto de Educação "Prof. Stélio Machado Loureiro".

As vivências ainda perduram, mesmo que em memórias:

Nossa! Até hoje. Eu estou aposentada, mas sonho que estou dando aula ainda. Às vezes estou lá em Nova York (não sei como eu vou parar lá). E penso: meu Deus do céu, no dia seguinte eu tenho aula. Como é que eu faço? Não posso faltar. Então é aquela alfabetização que eu falava, né? Eu fazia questão de todos os valores do "x", porque ele tem cinco valores, né? Então eu fazia o possível para chegar aqui. E acho que no sufoco eu acordava. Era muito gratificante. Agora eu só parei de lecionar porque meu filho e meu marido falaram: Chega! Você já trabalhou demais. Porque assim que eu me aposentei, o Instituto Noroeste me chamou para trabalhar, né? Aí eu trabalhei mais nove anos lá depois que saí do estado. Era a minha paixão. É isso que eu falo, né? Para ser professora a gente tem que gosta, né? A gente tem que se doar. E as crianças me adoravam. (COTARELLI, 2018)

Sobre essa formação inicial, Bueno (2002, p. 22) assim contribui: "[...] é preciso pensar a formação do professor como um processo, cujo início se situa muito antes do ingresso nos cursos de habilitação - ou seja, desde os primórdios de sua escolarização e até mesmo antes".

Quanto à motivação ou motivo da escolha para o magistério, as professoras apresentam distintas razões que as levaram a escolher essa profissão. Sobre sua vocação para ser professora, a professora Mesquita relata:

Eu sempre quis, desde menina brincava de professora. A gente já tem aquela vocação, gosto de criança, eu acredito que todos possuem uma vocação para alguma coisa, essa é a minha, é no que eu acredito. Eu sempre tive paciência, os meus netos vem aqui e têm liberdade total, falo: façam o que vocês quiserem, mecham na geladeira, façam tudo o que vocês quiserem. (MESQUITA, 2018)

A professora Cotarelli relata sobre sua vocação para ser professora expondo que gosta de criança, mas na sequência relata que queria ser médica, no entanto, isso não foi possível, pois seu pai tinha três filhos:

Eu gosto muito de crianças. Minha paixão é criança, então eu adorava. Eu também gosto de conhecer. Leio muito; gosto muito de leitura. Na verdade, eu queria ser médica, mas você já viu um pai com três filhos, né? Ele estudou os três filhos, né? E eu optei por professora, porque eu gosto muito de criança. (COTARELLI, 2018)

A falta de opção de outros cursos parece ser o que levou a professora Bilia a escolher o magistério, mas foi observado em suas narrativas que ela sofreu grande influência da madrinha, professora Bella. Sobre essa questão, ela relata: 
[...] quando eu terminei o ginásio que é quando a gente se define, eu tinha muita facilidade com geografia, coisas decorativas e gostava também de desenhos, mas não tinha aqui em Birigui, e todo o período que eu estudei foram meus padrinhos que custearam tudo e eles nunca melhoraram a condição e eu não pude sair de Birigui, tive que me conformar em ficar por aqui mesmo. Mas, sempre eu digo que não me arrependi nenhum pouquinho, se eu tivesse que fazer tudo de novo, eu faria. Eu sempre gostei muito de dar aula, porque eu amo crianças. Eu me doei demais, hoje não tenho mais joelho de tanto que eu usei ... eu me ajoelhava para conversar com as crianças, pegar na mãozinha e ficar na altura delas. Eu acho que é muito melhor para eles, eles são a minha vida. No ano de 1985 eu fui eleita a professora do ano. (BILIA, 2018)

A falta de opção de outros cursos também foi o motivo que levou a professora Marcório a optar pelo magistério:

Antigamente não tinha opção de escolher uma carreira, era só de professora e também só viajava para fazer curso quem tinha condição financeira boa. (MARCÓRIO, 2018)

Observa-se nos relatos que as respostas variam entre o gosto e a vocação para o magistério devido à falta de opção, à motivação econômica e à influência de alguém, como foi o caso da professora Bilia, pela professora Bella.

\begin{abstract}
Ah, era só o normal que a gente fazia aqui. Era depois do terceiro. Assim, você sai do Roberto Clark, ia para o Instituto, o Noroeste eu acho, fazia um exame de admissão, ai eu passei, fiz o ginásio né, mas fiquei um ano fora, voltei para o Instituto, me formei. Eu entrei no primeiro ano que abriu a escola normal. Eu fui da primeira turma, até um dia o diretor me homenageou. Em uma dessas festas que era dos meus bisnetos, eu era a exaluna mais velha de lá. Foi no ano passado que eu fui em uma festa, e eu levei o meu álbum, pois não tinha nada como provar que eu fui ex-aluna, ai ele viu o álbum, e queria que num dia de festa que eu ia estar lá com os meus bisnetos e ele ia aproveitar para me homenagear. No dia da festa eu fui e eu era a aluna mais velha. Nessa época já se saia para trabalhar, e o diretor chegou e perguntou se alguém queria dar aula, e eu tinha dezessete anos. (MESQUITA, 2018)
\end{abstract}

Mesquita estudou no curso normal ${ }^{3}$ do Colégio Metodista "Instituto Noroeste". E de acordo com o seu depoimento, sua turma de professoras foi a primeira a ser formada na cidade de Birigui, no ano de 1946.

A professora Cotarelli comenta sobre a sua formação, mencionando a Escola Normal e os cursos que gostava de fazer para se atualizar:

Escola normal. Mas eu fiz muitos cursos de especialização. Eu fiz CADES, eu fiz cursos de Português, Ciências, Matemática. Tanto cursinho depois do curso normal. Já havia ingressado, né? Eu ingressei em 61. Aí o diretor

\footnotetext{
${ }^{3}$ Antes da reforma proposta pelo Código de Educação, de 1933, as escolas primárias estavam divididas em preliminar e complementar, e os alunos aprovados nas matérias do segundo ano da Escola Normal tinham direito ao diploma de professor das escolas preliminares, enquanto os aprovados no terceiro ano podiam lecionar em escolas complementares. Segundo Tanuri (1979), em 1911, as escolas complementares foram transformadas em escolas normais primárias e as normais existentes (a Escola Normal da Capital, a de Itapetininga e a de São Carlos), em secundárias.
} 
mesmo me designava para fazer os cursos. Eu gostava muito de me atualizar. (COTARELLI, 2018)

A professora Bilia menciona o convite que obteve para lecionar, após se formar:

Minha formação foi o ensino Normal. Eu entrei no IE que era estadual e lá eu me formei, esse foi um período em que fui muito para minha casa. Eu fiz o ensino normal no IE, daí logo que me formei, fui convidada para lecionar (BILIA, 2018)

Algumas famílias valorizavam o magistério, naquele momento, assim como a família da professora Marcório:

Minha família sempre me apoiou e me incentivou a estudar. Naquela época não se tinha outra opção de curso para se fazer além da Escola Normal. Para estudar na Escola Normal Estadual "Prof. Stélio Machado Loureiro", tive que realizar um teste de admissão. E que este teste era obrigatório e realizado por todos os alunos que ingressavam na instituição. $\mathrm{O}$ mesmo ocorria do $8^{\circ}$ ano do Curso Ginasial para o $1^{\circ}$ ano do Curso Normal. E como meu padrasto era dentista, vinha de um 'mundo de estudos', queria muito que suas enteadas continuassem os estudos, as influenciando além do magistério a fazer a faculdade de Pedagogia. (MARCÓRIO, 2017)

Fiz magistério né, além de alguns cursos depois (MARCÓRIO, 2018).

Na Tabela 1 abaixo, encontra-se o nível de escolaridade das quatro professoras:

TABELA 1 - NÍVEL DE ESCOLARIDADE

\begin{tabular}{|c|c|c|}
\hline \multirow{2}{*}{ Professoras } & \multicolumn{2}{|c|}{ Escolaridade } \\
\cline { 2 - 3 } & Curso Normal $^{4}$ & $\begin{array}{c}\text { Curso superior } \\
\text { (Pedagogia) }\end{array}$ \\
\hline Mesquita & $\mathrm{X}$ & --- \\
\hline Cotarelli & $\mathrm{X}$ & -- \\
\hline Bilia & $\mathrm{X}$ & --- \\
\hline Marcório & $\mathrm{X}$ & $\mathrm{X}$ \\
\hline
\end{tabular}

Fonte: Elaboração própria.

As quatro professoras concluíram o curso normal, e apenas uma delas cursou o ensino superior, Pedagogia. Observamos nas narrativas que a professora Marcório estudou no $\mathrm{IE}^{5}$ "Prof. Stélio Machado Loureiro" e também fez o curso superior de

\footnotetext{
${ }^{4}$ A formação profissional de professores nos cursos das Escolas Normais era de grau secundário, enquanto a educação pedagógica ministrada na Escola de Professores do Instituto de Educação era de grau superior. (SÃ̃ PAULO, 1934, p. 614)

5 Após a promulgação do Decreto-Lei n.8530, de 2 de janeiro de 1946 (Lei Orgânica do Ensino Normal), o Estado de São Paulo promulgou o Decreto n.17698, de 26 de novembro de 1947. Por meio deste decreto ocorreram algumas mudanças nos cursos do Instituto de Educação "Caetano de Campos": o curso para a formação de professores primários passou a ser destinado à formação de professores primários e préprimários, com duração de três anos, denominado Curso Normal; o Curso Secundário deixou de ser dividido em fundamental e complementar e passou a ser Ginasial - Primeiro Ciclo - de quatro anos, com orientação e finalidades estabelecidos pela legislação federal; o Curso Primário, de cinco anos, foi subdividido em primário comum, de quatro anos, e complementar, de um ano; o Pré-Primário (Jardim da Infância) continuou com duração de três anos; continuaram os Cursos de Aperfeiçoamento, os de Administradores Escolares, para habilitação de diretores, orientadores de ensino e inspetores escolares, e apareceram os Cursos de Especialização, compreendendo os seguintes ramos: Educação Pré-Primária, Didática Especial de Curso Complementar Primário, Didática Especial do Ensino Supletivo, Didática
} 
Pedagogia ao longo da carreira. Podemos inferir que, principalmente após os anos de 1970, com a LDB 5.692/71 e o Estatuto do Magistério do Magistério Oficial do Estado de São Paulo, havia vantagens, necessidades e, posteriormente, a obrigatoriedade de se fazer a formação em nível superior, situação esta possivelmente que possibilitou a formação em curso superior da professora Marcório.

As professoras Mesquita, Cotarelli e Bilia concluíram o curso normal em escolas normais livres. As duas primeiras na Escola Normal Livre do Colégio Metodista Instituto Noroeste, Bilia na Escola Normal Livre do Colégio Sagrado Coração de Maria e a professora Marcório no Instituto de Educação "Prof. Stélio Machado Loureiro".

E, de acordo com os depoimentos dessas professoras que exerceram o magistério, inicialmente rural e depois urbano, foi conquistada uma ascensão sociocultural em relação aos seus familiares, a partir dessa formação inicial, e além disso, seus filhos adquiriram capital cultural escolar além do delas, empreendendo hoje em diversas áreas.

A leitura das quatro narrativas, entrevistas transcritas, dá visibilidade às representações dessas professoras acerca de escola e atuação docente e discente. Como afirma Nóvoa (1999, p. 16) “[...] mesmo quando a missão de educar é substituída pela prática de um ofício e a vocação cede lugar à profissão, as motivações originais não desaparecem".

Por essa razão, a partir das escolhas dos caminhos percorridos, as referidas professoras vão dando voz à "vocação/motivação" escrevendo a própria história, que as forma sobremaneira, na vivência da sala de aula.

\section{CONSIDERAÇÕES FINAIS}

Dessas quatro professoras, três eram filhas de trabalhadores da classe média, sitiantes, e as três nasceram na zona rural, somente a professora Marcório nasceu na cidade. A professora Mesquita chegou a morar no colégio interno da cidade de Cafelândia/SP por um ano, mas depois disso, seus pais resolveram mudar-se para a cidade de Birigui/SP. A professora Bilia, com três anos de idade passa a morar com uma família na cidade de Birigui/SP e a experiência vivida quando criança com uma professora leiga a leva a buscar pelo magistério. Já as professoras Mesquita, Cotarelli e Marcório prosseguem nos estudos e se tornam professoras em virtude da falta de opção e também por serem pessoas da classe média que sofrem influências de familiares, principalmente a professora Marcório, que nasceu na cidade, e uma vez que seu padrasto era dentista, portanto, já havia realizado curso superior, incentivava muito suas filhas e enteadas a serem professoras.

Também é possível considerar, de acordo com Bueno (2002), que foi durante o percurso da vida escolar que as professoras foram se constituindo, construindo-se docentes.

Especial do Desenho e Artes aplicadas, Didática Especial de Música e Canto (SÃO PAULO, 1947, p.194195). 
Os relatos ainda evidenciam o grande interesse pela educação e pela busca da profissão docente, quando afirmam gostar de criança, e também de ler, entre outros aspectos sinalizados, no início da vida escolar nas escolas rurais.

No que se refere ao nível de escolaridade, nota-se que somente a professora Marcório cursou Pedagogia, talvez por não existirem mais cursos de Pedagogia oferecidos na região e porque esse curso, ao longo da carreira, principalmente após os anos de 1970, com a reforma da Lei $n^{\circ} 5692 / 71$ e o Estatuto do Magistério, oferecia vantagens, necessidades e, posteriormente, a obrigatoriedade de se fazer a formação em nível superior, situação esta da professora Marcório.

Diante desses dados, é possível afirmar que as quatro professoras passaram pela formação inicial em escolas primárias e curso normal e que foram construindo uma história da docência em meio às experiências vividas, partindo da vocação/motivação e participando da construção dessa história de professores no município de Birigui/SP.

\section{REFERENCIAS}

ALBERTI, Verena. O que documenta a fonte oral? Possibilidades para além da construção do passado. CPDOC-FGV, 1996. II SEMINÁRIO DE HISTÓRIA ORAL. Centro de Estudos Mineiros da Faculdade de Filosofia e Ciências Humanas da Universidade Federal de Minas Gerais, em Belo Horizonte, de 19 a 20 de setembro de 1996. Disponível em: <https://cpdoc.fgv.br/producao_intelectual/arq/869.pdf>. Acesso em: 23 janeiro de 2019.

ALBERTI, Verena. De "versão" a "narrativa" no Manual de história oral. CPDOCFGV, 2012. XI ENCONTRO NACIONAL DE HISTÓRIA ORAL "MEMÓRIA, DEMOCRACIA E JUSTIÇA". Universidade Federal do Rio de Janeiro, no Instituto de Filosofia e Ciências Humanas/Instituto de História, de 10 a 13 de julho de 2012. Disponível em: <http://cpdoc.fgv.br/acervo/historiaoral/base>. Acesso em: 25 jan.de 2019.

BOSI, Ecléa. O tempo vivo da memória: ensaios de Psicologia Social. São Paulo: Ateliê Editorial, 2003.

BUENO, Belmira Oliveira. O método autobiográfico e os estudos com histórias de vida de professores: a questão da subjetividade. Educação e Pesquisa, v. 28, n. 1. São Paulo: USP, 2002, p.11-30.

LENGERT, Rainer. Profissionalização docente: entre vocação e formação. Revista de Educação, Ciência e Cultura, v. 16, n. 2, jul./dez. 2011, UNILASALLE.

MATOS, Márcio José Rigueiro; SERRA, Áurea. Esteves; THOMAZIN, Bruna Nogueira. Céris Spínola, de aluna a professora: a docência na educação básica. FATEB Científica, v. 01, n.1, julho/dezembro de 2017.

NÓVOA, António. O passado e o presente dos professores. In: NÓVOA, António (Org.). Profissão Professor. Lisboa: Porto Editora, 1999, p. 13-34. 
SERRA, Áurea Esteves. A formação do professor alfabetizador em Birigui (19611976). Araraquara, SP: Junqueira \& Marim; São Paulo: FAPESP, 2007.

SERRA, Áurea Esteves. Algumas reflexões sobre as escolas rurais do município de Birigui/SP - Brasil. Revista Boletín Redipe. Escenarios de la education, ensenanza y el aprendizaje, v.3, n.10 octubre de 2014, p.56 - 79.

TARDIF, Maurice. Saberes profissionais dos professores e conhecimentos universitários: elementos para uma epistemologia da prática profissional dos professores e suas consequiências em relação à formação para o magistério. Revista Brasileira de Educação, Associação Nacional de Pós-graduação e Pesquisa em Educação, n. 13, p. 524, jan./fev./mar./abr., $2000 . \quad$ Disponível em <http://www.anped.org.br/rbe/rbedigital/RBDE13/RBDE13_05_MAURICE_TARDIF. pdf $>$. Acesso em: 26 de janeiro de 2019.

\section{Fontes Orais}

BILIA, A.B. Ex-professora primária rural de Birigui. Mar/2018.

COTARELLI, M.G. Ex-professora primária rural de Birigui. Mar/2018.

MARCÓRIO, M. C. S. Ex-professora primária rural de Birigui. Mar/2018.

MESQUITA, I. F. Ex-professora primária rural de Birigui. Mar/2018.

Recebido em: 07/02/2019

Aprovado em: 04/04/2019 